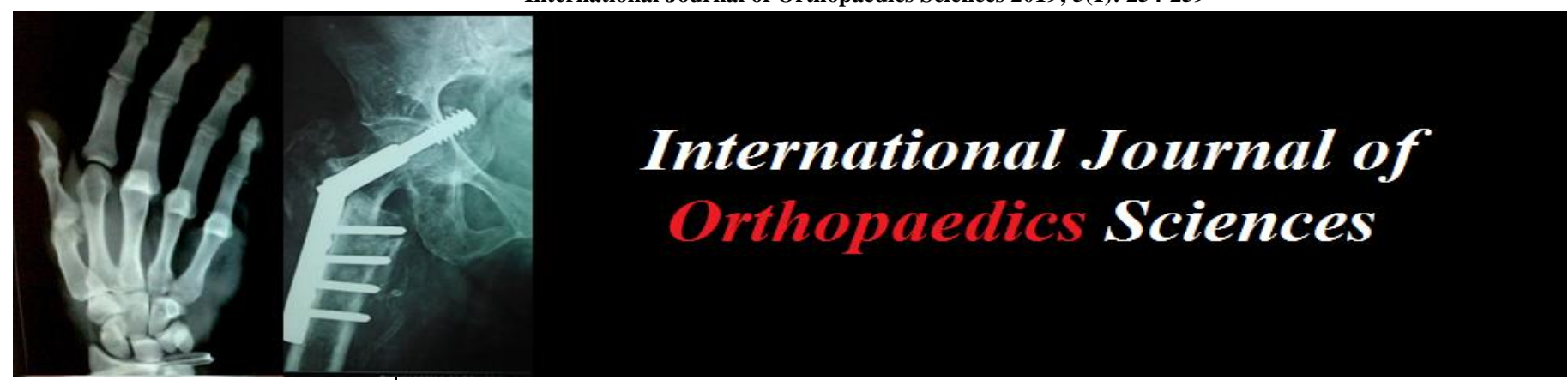

ISSN: $2395-1958$

IJOS 2019; 5(1): 254-259

(C) 2019 IJOS

www.orthopaper.com

Received: 04-11-2018

Accepted: 07-12-2018

Dr. J Dhoom Singh

Associate Professor, Department of Orthopaedics, Deccan College of Medical Sciences, Hyderabad, Telangana, India
Correspondence

Dr. J Dhoom Singh

Associate Professor, Department of Orthopaedics, Deccan College of Medical Sciences, Hyderabad, Telangana, India

\section{Comparison of clinical and functional outcome of intra- articular fractures of distal end of radius with conservative versus surgical treatment: A prospective study}

\section{Dr. J Dhoom Singh}

DOI: https://doi.org/10.22271/ortho.2019.v5.i1e.44

\begin{abstract}
A prospective study constituted a total of $n=90$ subjects with intra-articular distal end of radius fractures was conducted in Kakatiya Medical College, Warangal, Telangana, India, for a period of eighteen months. The objective of the present study was management for a distal end radius fracture for accurate restoration of range of motion and grip strength and to achieve a good functional outcome with return to normal functional status of the patient at the earliest possible and to compare clinical and functional outcome with conservative and surgical management. The present study sample consisted of $n=90$ subjects of which $n=44$ subjects were treated with conservative management, $n=46$ with surgical method. Among $\mathrm{n}=46$ cases treated surgically, $\mathrm{n}=11$ were managed by pinning, $\mathrm{n}=11$ by ligamentotaxis with external fixator and $n=24$ with plating. Excellent results were observed in $30 \%$ of the cases in conservative group and $47.5 \%$ in surgical group. Excellent and good results were seen in $85 \%$ cases in plating group and $52.17 \%$ in K-wire in surgically managed group. Excellent and good outcome results in conservative group were observed in stable, minimally comminuted and minimally displaced fracture pattern. Excellent and good outcome results were seen in many of such fracture pattern among surgical group. The best outcome or results were seen among young individuals.
\end{abstract}

Keywords: Conservative treatment, distal radius fracture, ligamentotaxis, plating

\section{Introduction}

Fractures of distal radius are one of the most common fractures of the upper limb, seen in the Orthopaedic Department, and constitute $17 \%$ of all fractures and $75 \%$ of all forearm fractures ${ }^{[1]}$. Fractures of the distal radius usually occur as a result of high energy trauma in younger individuals with good bone density and are associated with substantial articular and periarticular tissue injury. These fractures can be managed both conservatively and surgically. Non-operative management is reserved for undisplaced stable fractures and requires no fixation ${ }^{[2]}$.

Symptomatic relief is achieved by immobilization with below elbow cast. However, certain types of distal radial fractures require surgical management and many modalities of treatment are available. Various surgical options available are closed reduction and percutaneous pinning with Kirschner wires, bridging and nonbridging external fixators and open reduction and internal fixation with locking compression plates.

The objectives of management for a distal end radius fracture should be accurate restoration of range of motion and grip strength and to achieve a good functional outcome with return to normal functional status of the patient at the earliest possible ${ }^{[3]}$ and minimizing the chances of post traumatic arthritis.

The aim of the present study was to compare the clinical and functional outcome of intraarticular fractures of the distal end of the radius with conservative and surgical management.

\section{Materials and Methods}

A prospective study constituted a total of $n=90$ subjects with intra-articular distal end of radius fractures was conducted in Kakatiya Medical College, Warangal, Telangana, India, for a period of eighteen months. 
The patients who attended the outpatient or the emergency service and admitted to the Department of Orthopaedics, Mahatma Gandhi Memorial (MGM) Hospital, Warangal, Telangana, India, with distal end radius fracture satisfying the inclusion criteria were considered for the present study and with follow up from the time of admission to a minimum of 6 months postoperative period was done. Patient was informed about the study in all aspects and informed consent was taken for their inclusion in the study. Ethical Committee approval was taken from the College Ethical Board.

The study sample consisted of $\mathrm{n}=90$ subjects and all these patients were included with pre-defined inclusion and exclusion criteria in this study. Inclusion criteria included patients with intra-articular fractures of distal end of radius, patients presented within 3 weeks after injury, male and female subjects of age 20-80 yrs, patients who did not have other associated fractures in the ipsilateral upper limb, patients who were medically fit for surgery, patients who had given their consent for the procedure. Exclusion criteria included patients, who were medically unfit for the surgery, patients not willing for surgery. Surgical methods adopted were pinning, ligamentotaxis with External Fixator and Plating.

After the patient with intra-articular distal end radius fracture was admitted / planned to treat on outpatient basis, all the necessary clinical details were recorded in the proforma prepared for this study.

The patients with suspected distal radius fracture were subjected to necessary clinical and radiological evaluation. Anteroposterior (AP) and lateral views of the wrist joint on both the sides was obtained at the time of presentation. The radiographs were assessed in terms of loss of palmar tilt or presence of dorsal tilt, radial shortening and loss of radial inclination.

Patients were evaluated and managed either conservatively or by surgical methods. All the patients planned for surgical management were admitted and the following investigations were done routinely pre-operatively:

Blood: $\mathrm{Hb} \%$, bleeding time, clotting time, blood grouping and cross matching, FBS and PPBS, blood urea and serum creatinine.

Urine: Albumin, sugar, microscopy

Imaging: Wrist joint - AP and Lateral view, chest X-ray PA view, CT of distal radius with wrist was done for cases which required appreciation of the fracture pattern. In select cases with extensive communition and wide displacement of the fracture fragments, CT scan was taken to get a better understanding of the fracture configuration and to plan for surgical fixation.

The fractures were classified according to Frykman's classification. Fractures with minimal displacement and without communition were assigned to the conservative management group while those displaced and communited fractures were treated surgically. The patients in the conservative group were mostly managed in the outpatient or the emergency department and were sent home and asked to review as per the suggested time frames.

The procedures for the patients managed surgically were performed under either general anaesthesia or supraclavicular block under broad spectrum intravenous antibiotic cover which was continued for 3 days postoperatively. The various surgical modes of fixation employed were closed reduction and percutaneous pinning in $\mathrm{n}=12$ subjects while ligamentotaxis with external fixator application was done in $n$ $=12$ subjects and the remaining $\mathrm{n}=22$ subjects were managed by open reduction and internal with locking compression plates through the volar Henry's approach. The patients fixed with locking compression plates were managed by first wound inspection, after 48 hours followed by regular dressings and suture removal was done on the 12th postoperative day. Patients were not allowed to lift heavy weight for $12-16$ weeks.

Implants used were K-wires - $1 \mathrm{~mm}, 1.5 \mathrm{~mm}$ and $2 \mathrm{~mm}$, External fixation by Schanz pins $-2.5,3.5 \mathrm{~mm}$, Clamps, Connecting rods, Ellis plate, Distal radial LCP.

\section{Methodology}

Out of $\mathrm{n}=90$ subjects, $\mathrm{n}=44$ subjects were treated with conservative management, $n=46$ with surgical management. Among $n=46$ cases treated surgically, $n=11$ were managed by pinning, $\mathrm{n}=11$ by ligamentotaxis with external fixator and $\mathrm{n}=24$ with plating at the Dept. of Orthopaedics, Mahatma Gandhi Memorial (MGM) Hospital, Warangal, Telangana, India.

The patients who were not willing for surgical management were managed conservatively. For the patients who underwent either surgical or conservative management, follow-up was done for a period of 6 months. After initial resuscitation in the emergency, closed fractures were splinted and operated at the earliest. Open fractures were excluded.

A fracture with no pain on palpation or attempted motion, no increase in warmth at the fracture site, no discomfort on carrying weights and serial roentgenograms demonstrated bone trabaculae crossing the fracture site was considered united. On every visit, clinical, functional, radiological and overall results were recorded according to PRWE (patientrated wrist evaluation questionnaire) score and Demerit point system Score Demerit score ${ }^{[4]}$ and DASH score (The Disabilities of the Arm, Shoulder and Hand score) ${ }^{[5]}$. Functional grading was noted depending on pain, mobility and work. Radiological grading was made based on varus of valgus deformity, shortening, sign of osteoarthritis and union of fracture.

After the completion of the treatment, patients were discharged and called for follow up at outpatient level, at regular intervals for serial clinical and radiological evaluation.

\section{Surgical procedure}

Preference was given for management of life threatening emergencies i.e., head injury, blunt trauma abdomen, blunt trauma chest and patients were taken up for orthopaedic surgery once patient is out of danger, till then fractures were managed with slab application and elevation.

The patient was positioned supine with affected wrist on side table pinning. Image intensifier was positioned under the armboard so as to visualise and identify the distal radius, distal ulna and the articular surface in AP and lateral views.

Usually, the radial styloid is pinned to the proximal shaft in a reduced position. Once the lateral cortex is reconstituted, the intermediate column (lunate facet) is pinned from dorsal ulnar to proximal radial. Finally the central impaction fragments can be supported using subcondral transverse wires. Plaster was applied if fracture fixation was doubtful.

\section{External fixator application}

Schanz pins were fixed to lateral border of radius (minimum 3 pins) after stab incision at the pinned pin site and drilling it. 
Similar procedure was done on radial border of $2^{\text {nd }}$ metacarpal. After traction and counter traction the fracture reduction was done under image intensifier and pins fixed to connecting rod with clamp.

\section{Palmar plate fixation}

The skin incision was centered over the PCR was applied through Flexor carpi radialis (PCF), radial artery was mobilized and dissection was carried out radially by releasing the brachiocardialis tendon from the radial styloid. The pronator quadratus muscle was released from its radial attachment.

Anatomic reduction of both the radial and the intermediate columns was done. Once the columns were aligned, the fracture was fixed to the palmar plate avoiding penetration of the articular surface and wound was closed in layers.

Post-operative treatment protocol followed was routine antibiotics, analgesics and evaluation by $\mathrm{x}$-rays.

The wrist and finger movements were started on the second postoperative day based on the pain tolerance of the patient except for those fixed with External fixator or Kirschner wires alone. Those patients fixed with K-wires were initially given below elbow cast and was advised mobilization by 3 weeks, after the removal of the cast.

The Kirschner wires were removed at 3 weeks and active wrist movements were advised while the external fixator removal was done after 6 weeks and physiotherapy was started to promote good range of movements of the wrist joint.

The patient follow-up assessment was done at 1 and 6 weeks, and at 3 and 6 months for assessment of clinical and functional capabilities with regard to daily activities and complications if any.

Records available in the form of admission notes, operative notes, progress notes and follow up OPD records were analysed. Fractures of the ankle were evaluated using plain radiographs in antero-posterior, lateral and mortise views.

\section{Results and Discussion}

The present study constituted $\mathrm{n}=90$ patients with distal radius fractures. Out of which $\mathrm{n}=61(67.78 \%)$ were male and $\mathrm{n}=29(32.22 \%)$ were female. The higher incidence of male cases in distal end radius could be attributed to highly active work group and also the fact that in our Indian setup, the female population largely works indoors or in the agricultural fields.

Table 1: Gender distribution in two groups

\begin{tabular}{|c|c|c|c|c|c|c|}
\hline \multirow{2}{*}{ Gender } & \multicolumn{2}{|c|}{ Conservative management } & \multicolumn{2}{c|}{ Surgical management } & \multicolumn{2}{c|}{ Total } \\
\cline { 2 - 7 } & No. & $\mathbf{\%}$ & No. & \% & No. & \% \\
\hline Male & 23 & 52.27 & 38 & 82.61 & 61 & 67.78 \\
\hline Female & 21 & 47.73 & 8 & 17.39 & 29 & 32.22 \\
\hline Total & 44 & 100 & 46 & 100 & 90 & 100 \\
\hline
\end{tabular}

The minimum age of the subjects was 20 yrs and maximum 80 yrs with mean age 40.35 yrs. Most common age group was $41-50$ yrs $(36.36 \%)$ with mean age being $42.8 \%$ yrs in conservative group. In surgical group most common age group was $20-30$ yrs $(32.61 \%)$ with mean age being 26.97 yrs (Table 2).

Table 2: Distribution of patients in each age group

\begin{tabular}{|c|c|c|c|c|}
\hline \multirow{2}{*}{ Age (years) } & \multicolumn{2}{|c|}{ Conservative management } & \multicolumn{2}{c|}{ Surgical management } \\
\cline { 2 - 5 } & No. & \% & No. & \% \\
\hline $20-30$ & 12 & 27.27 & 15 & 32.61 \\
\hline $31-40$ & 6 & 13.64 & 14 & 30.43 \\
\hline $41-50$ & 16 & 36.36 & 8 & 17.39 \\
\hline $51-60$ & 4 & 9.09 & 7 & 15.22 \\
\hline $61-70$ & 4 & 9.09 & 0 & 0 \\
\hline $71-80$ & 2 & 4.55 & 2 & 4.35 \\
\hline Total & 44 & 100 & 46 & 100 \\
\hline Mean \pm SD & \multicolumn{2}{|c|}{$41.28 \pm 13.52$} & \multicolumn{2}{c|}{$38.97 \pm 13.28$} \\
\hline
\end{tabular}

Samples are age matched with $\mathrm{p}=0.387$

Road traffic accident (RTA) was the most common mode of injury in $n=41$ subjects $(45.56 \%)$, followed by self-fall in $n=$ 39 subjects $(43.33 \%)$ (Table 3$)$. Right side injury was observed to be more common in $n=47(52.22 \%)$ (Table 4$)$. Deepak et al. ${ }^{[6]}$ and Gunaki et al. ${ }^{[7]}$ reported similar results in their studies.

Table 3: Distribution of mode of injury in two groups

\begin{tabular}{|c|c|c|c|c|}
\hline \multirow{2}{*}{ Mode of injury } & \multicolumn{2}{|c|}{ Conservative management } & \multicolumn{2}{c|}{ Surgical management } \\
\cline { 2 - 5 } & No. & $\mathbf{\%}$ & No. & \% \\
\hline Assault & 2 & 4.55 & 2 & 4.35 \\
\hline Fall from height & 2 & 4.55 & 4 & 8.69 \\
\hline Road traffic accident & 11 & 25 & 30 & 65.22 \\
\hline Self-fall & 29 & 65.90 & 10 & 21.74 \\
\hline Total & 44 & 100 & 46 & 100 \\
\hline
\end{tabular}

Self-fall is significantly more associated with conservative group with $\left(\mathrm{p}=0.004^{*}\right)$ 
Table 4: Distribution of side in two groups

\begin{tabular}{|c|c|c|c|c|}
\hline \multirow{2}{*}{ Side } & \multicolumn{2}{|c|}{ Conservative management } & \multicolumn{2}{c|}{ Surgical management } \\
\cline { 2 - 5 } & No. & $\mathbf{\%}$ & No. & \% \\
\hline Left & 24 & 54.55 & 19 & 41.30 \\
\hline Right & 20 & 45.45 & 27 & 58.70 \\
\hline Total & 44 & 100 & 46 & 100 \\
\hline
\end{tabular}

The most common fracture pattern as classified was Fryman's type III in $\mathrm{n}=38$ subjects $(42.22 \%)$ and $\mathrm{AO}$ type $\mathrm{C} 2.2$ in $\mathrm{n}=$ 16 subjects (17.78\%). Fryman's type III was the most common fracture in both the groups followed by Type VIII, AO Type C3.2, C3.3 (Table 5).

Table 5: Distribution of classification in two groups

\begin{tabular}{|c|c|c|c|c|}
\hline \multirow{3}{*}{ Classification } & \multicolumn{2}{|c|}{ Conservative management $(n=44)$} & \multicolumn{2}{|c|}{ Surgical management $(n=46)$} \\
\hline & No. & $\%$ & No. & $\%$ \\
\hline & \multicolumn{4}{|c|}{ Fryman's classification } \\
\hline Type I & - & - & - & - \\
\hline Type II & - & - & - & - \\
\hline Type III & 20 & 45.45 & 18 & 39.13 \\
\hline Type IV & 4 & 9.09 & 1 & 2.17 \\
\hline Type V & - & - & - & - \\
\hline Type VI & - & - & - & - \\
\hline Type VII & 7 & 15.91 & 14 & 30.43 \\
\hline \multirow[t]{2}{*}{ Type VIII } & 13 & 29.55 & 13 & 28.26 \\
\hline & \multicolumn{4}{|c|}{ AO Classification } \\
\hline B1.1 & 7 & 15.91 & 6 & 13.43 \\
\hline B1.2 & 7 & 15.91 & 1 & 2.17 \\
\hline B2.2 & 2 & 4.55 & 2 & 4.35 \\
\hline B3.1 & 5 & 11.36 & 4 & 8.70 \\
\hline B3.2 & 0 & 0.0 & 8 & 17.39 \\
\hline C1.2 & 2 & 4.55 & 0 & 0.0 \\
\hline $\mathrm{C} 1.3$ & 2 & 4.55 & 0 & 0.0 \\
\hline $\mathrm{C} 2.2$ & 6 & 13.63 & 10 & 21.74 \\
\hline C3.1 & 6 & 13.63 & 5 & 10.87 \\
\hline $\mathrm{C} 3.2$ & 5 & 11.36 & 9 & 19.57 \\
\hline C3.3 & 2 & 4.55 & 1 & 2.17 \\
\hline
\end{tabular}

Mean time of union at 6 weeks was seen in $n=20(45.45 \%)$ in conservative management group and in $n=40$ subjects $(86.96 \%)$ in surgical treatment group. In conservative group at 3 months mean time of union was in $\mathrm{n}=22$ subjects $(50 \%)$ and in $n=6$ subjects $(13.04 \%)$ in surgical treatment group. Mean time of union was significantly less (6 weeks) in surgical management group similar to the previous reports ${ }^{[8]}$. While in conservative group the time of union was 3 months in $50 \%$ of the cases. $4.55 \%$ cases had union at 6 months in conservative group and none in surgical group (Table 6). Delayed union was observed among postmenopausal female and aged male cases.

Table 6: Comparison of time of union in two groups

\begin{tabular}{|c|c|c|c|c|}
\hline \multirow{2}{*}{ Time of union } & \multicolumn{2}{|c|}{ Conservative management } & \multicolumn{2}{c|}{ Surgical management } \\
\cline { 2 - 5 } & No. & \% & No. & $\%$ \\
\hline 6 weeks & 20 & 45.45 & 40 & 86.96 \\
\hline 3 months & 22 & 50.0 & 6 & 13.04 \\
\hline 6 months & 2 & 4.55 & 0 & 0.0 \\
\hline Total & 44 & 100 & 46 & 100 \\
\hline
\end{tabular}

Time of union is significantly less (6 weeks) associated with surgical management $(\mathrm{p}=0.001 *)$

In conservative group the mean \pm SD pain score was $19.24 \pm$ 11.21 and $14.17 \pm 8.46$ for surgical group (Table 7). Mean pain score was significantly less $(\mathrm{p}=0.007)$ in surgical management group. In the surgical group least mean pain score was noted in plating group and more in K-wire group. Our results are in confirmation with the observations reported earlier by Chen et al ${ }^{[9]}$ and Carrozzella and Stern ${ }^{[10]}$.

Table 7: Comparison of pain score in two groups

\begin{tabular}{|c|c|c|c|c|}
\hline \multirow{2}{*}{ Pain score } & \multicolumn{2}{|c|}{ Conservative management $(\mathbf{n}=\mathbf{4 4})$} & \multicolumn{2}{c|}{ Surgical management $(\mathbf{n}=\mathbf{4 6})$} \\
\cline { 2 - 5 } & No. & $\mathbf{\%}$ & No. & \% \\
\hline $1-10$ & 14 & 31.82 & 22 & 47.83 \\
\hline $11-20$ & 15 & 34.09 & 14 & 30.43 \\
\hline $21-30$ & 7 & 15.91 & 5 & 10.87 \\
\hline $31-40$ & 4 & 9.09 & 5 & 10.87 \\
\hline$>40$ & 4 & 9.09 & 0 & 0.0 \\
\hline Total & 44 & 100.0 & 46 & 100.0 \\
\hline Mean \pm SD & $19.24 \pm 11.21$ & & & $14.17 \pm 8.46$ \\
\hline
\end{tabular}

Mean pain score is significantly less associated with surgical management with $p=0.065^{*}$ 
Function score comparison in two groups is presented in Table 8. Mean function score is significantly less $(\mathrm{p}=0.003)$ cases with surgical treatment group, values being 28.4 for conservative group and 19.25 for surgical group.

Table 8: Comparison of Function Score in two groups

\begin{tabular}{|c|c|c|c|c|}
\hline \multirow{2}{*}{ Pain score } & \multicolumn{2}{|c|}{ Conservative management } & \multicolumn{2}{c|}{ Surgical management } \\
\cline { 2 - 5 } & No. & \% & No. & $\%$ \\
\hline $1-10$ & 4 & 10.0 & 7 & 17.5 \\
\hline $11-20$ & 10 & 25.0 & 11 & 45.0 \\
\hline $21-30$ & 6 & 15.0 & 1 & 27.5 \\
\hline $31-40$ & 8 & 20.0 & 3 & 2.5 \\
\hline$>40$ & 12 & 30.0 & 40 & 100.0 \\
\hline Total & 40 & 100.0 & \multicolumn{2}{c|}{$19.25 \pm 11.22$} \\
\hline Mean \pm SD & \multicolumn{2}{|c|}{$28.4 \pm 25.55$} & \\
\hline
\end{tabular}

Mean function is significantly less in patients with surgical management with $\mathrm{p}=0.003 * *$

Mean loss of movement was less $(29.5 \%)$ in surgical group compared to conservative group (35.2\%). Among surgical group least was in plating (30\%) and more in K-wire (35\%).

The percentage of loss of movement did not correlate with the time of union (TOU). Even the patients with time of union of 6 weeks had greater percentage of loss of movement and also patients with TOU of 3 months had good range of movements. Similarly, pain and function score at 6 months follow up did not correlate with TOU.

Mean dorsi-flexion in conservative was $54^{\circ}$ whereas, in surgical group $65^{\circ}$. Mean palmar-flexion for conservative group was $60^{\circ}$ while $62^{\circ}$ for surgical group. Mean arc of Dorso-palmar flexion for conservative group was $109^{\circ}$ and $132^{\circ}$ for surgical group.

Mean radial deviation was $8^{\circ}$ for conservative group and surgical group. Mean ulnar deviation for conservative group was $17^{\circ}$ and $19^{\circ}$ for surgical group. Mean arc of radio-ulnar deviation for conservative group was $26^{\circ}$ and $27^{\circ}$ for surgical group.

Mean pronation for conservative group was $72^{\circ}$ and $69^{\circ}$ for surgical group. Mean supination for conservative group was $142^{\circ}$ and $149^{\circ}$ for surgical group. The present study results are in correlation with previous reported results by Kapoor et al ${ }^{[11]}$. In surgical group, all the movements were maximum in plating group and minimum in $\mathrm{K}$-wire group.

Mal-union was seen in $30 \%$ cases of conservative group and $10 \%$ in surgical group. In $\mathrm{K}$-wire group $30 \%$ and none in plating. Mal-union was seen in case of fracture with excess initial displacement, excess comminution treated conservative or K-wire. Stiffness of wrist and fingers was seen in $9 \%$ in both the groups. Shoulder hand syndrome was seen in $10 \%$ in conservative group and none in surgical group. Osteodystrophy was seen in 5\% conservative group and none in surgical group.

Intra-articular step was seen in $27.27 \%$ cases of conservative group and $41.30 \%$ in surgical group, In contrast to the studies made by Knirk and Jupiter ${ }^{[12]}$ and Kapoor et al ${ }^{[11]}$.

Radial inclination was lost in $45.45 \%$ cases of conservative group and $28.26 \%$ in surgical group. Radial inclination was best restored with plating $(82.61 \%)$ in our study and least with K-wire (28.26\%).

Radial length was lost in $45.45 \%$ cases of conservative group and $30.43 \%$ in surgical group. Radial length was best restored with plating $(82.25 \%)$ in our study and least with K-wire $(67.78 \%)$ in contrast to other studies Horesh et al ${ }^{[13]}$ and Kapoor et al ${ }^{[11]}$ where it is best restored with external fixation.

External fixation has been commonly used in the management of these fractures and it serves to improve parameters such as radial length and dorsal tilt ${ }^{[14-16]}$. External fixation is popular for the treatment of displaced fractures of the distal radius. External fixator application can be supplemented with $\mathrm{K}$ wire fixation for added stability as and when required.

Complication like mal-nutrition was $25 \%$ in conservative group and $10.87 \%$ in surgical group. Stiffness of wrist and fingers was noticed in $10 \%$ in both the groups. Shoulder hand syndrome was seen in $11.36 \%$ in conservative group and none in surgical group. Osteodystrophy was seen in $4.55 \%$ in conservative group and none in surgical group.

In the surgical group plating group did not have any procedure related complications. K-wire and external fixator group had pin tract infection in $10.87 \%$ of cases but were managed with pin-tract care.

Excellent results were observed in $30 \%$ of the cases in conservative group and $47.5 \%$ in surgical group. Excellent and good results were seen in $85 \%$ cases in plating group and $52.17 \%$ in K-wire in surgically managed group. Our results are similar to the results reported earlier $[11,12,17]$.

Excellent and good outcome results in conservative group were observed in stable, minimally comminuted and minimally displaced fracture pattern. Excellent and good outcome results were seen in many of such fracture pattern among surgical group. The best outcome or results were seen among young individuals.

The importance of anatomic reduction in getting a good functional outcome has been demonstrated in previous studies.

\section{Conclusion}

Distal radial fracture is one of the most common injuries to the musculoskeletal system, which were managed both by conservative and surgical methods. There are advantages as well as disadvantages in each method. The individual fracture analysis determines their therapeutic options.

From the present study series, we can conclude that surgical management is better compared to conservative group in the treatment of comminuted and displaced intra articular fractures of distal end of radius. Therefore, we cannot generalize one treatment method for all fracture patterns and treatment should be individualized to a particular fracture.

\section{References}

1. Margaret McQueen M, Rockwood CA. Fractures of the distal radius and ulna. Chapter-32, In: Rockwood CA, Matsen FA, Wirth MA, Lippitt SB, editors, Upper Extremity. 3rd edition Philadelphia: Saunders, 2004, 455519.

2. Abbaszadegan H, Conradi P, Jonsson U. Fixation not needed for undisplaced Colles' fracture. Acta Orthop Scand. 1989; 60(1):60-62. 
3. Altissimi M, Antenucci R, Fiacca C, Mancini GB. Longterm results of conservative treatment of fractures of the distal radius. Clin Orthop Relat Res. 1986; 206:202-210.

4. Saito H, Shibata M. Classification of Fracture at the Distal End of the Radius with Reference to Treatment of Comminuted Fractures. In: Boswick JA, Lea and Febiger. Current Concepts in Hand Surgery: 1st ed. Philadelphia: Lea \& Febiger, 1983, 129-45.

5. Hudak PL, Amadio PC, Bombardier C. Development of an Upper Extremity Outcome measure: The DASH (Disabilities of Arm, Shoulder and hand). Published Jun, 1996.

6. Deepak CD, Gopalakrishna G, Ravoof A. Surgical management of distal end radius fractures by ligamentotaxis. Int J Health Sci Res. 2014; 4(4):106-110.

7. Gunaki RB, Ranka RP. Management of fractures of distal third of radius. Indian Journal Orthopaedics. 1998; 80B(4):665-669.

8. Hirashima T, Kim WC, Kawamoto K, Yoshida T, Kubo T. Evaluating Bone Union of Distal Radius Fractures by Measuring Impedance Values. The Cutting Edge. 2009; 32(1).

9. Chen CE, Juhn RJ, Ko JY. Treatment of Distal Radius Fractures with Percutaneous Pinning \& Pin-in-plaster. Hand. 2008; 3(3):245-250.

10. Carrozzella J, Stern PJ. Treatment of comminuted distal radius fractures with pins \& plaster. Hand Clinic. 1988; 4(3):391-397.

11. Kapoor H, Agarwal A, Dhaon BK. Displaced intraarticular fractures of distal radius: a comparative evaluation of results following closed reduction, external fixation \& open reduction with internal fixation. Int $\mathbf{J}$ Care Injured. 2000; 31(2):75-79.

12. Knirk JL, Jupiter JB. Intra-articular fractures of the distal end of the radius in young adults. J Bone Joint Surg Am. 1986; 68(5):647-659.

13. Horesh Z, Volpin G, Hoerer D, Stein H. The surgical treatment of severe comminuted intra-articular fractures of the distal radius with the small AO external fixation device. A prospective three-and-one-half-yr follow-up study. Clin Orthop Relat Res. 1991; 263:147-153.

14. McAuliffe JA. Combined internal and external fixation of distal radius fractures [J]. Hand Clin. 2005; 21(3):395406.

15. Ruch DS, Papadonikolakis A. Volar versus dorsal plating in the management of intra-articular distal radius fractures [J]. J Hand Surg Am. 2006; 31(1):9-16.

16. Werber KD, Raeder F, Brauer RB et al. External fixation of distal radial fractures: four compared with five pins: a randomized prospective study [J]. J Bone Joint Surg Am. 2003; 85(4):660-666.

17. Arora J, Kapoor H, Malik A, Bansal M. Closed reduction \& plaster cast immobilization vs. external fixation in comminuted intra-articular fractures of distal radius. IJO. 2004; 38(2):113-117. 